\title{
(1) \\ VALORES QUE MOTIVAM MULHERES DE BAIXA RENDA A COMPRAR PRODUTOS DE BELEZA
}

MARIANA NAZARÉ LIVRAMIENTO

Mestre em Administração pelo Departamento de Administração da

Pontifícia Universidade Católica do Rio de Janeiro (PUC-RJ).

Gerente de produto do Departamento de Marketing do Laboratório Servier do Brasil. Estrada Bandeirantes, 4.21 1, Jacarepaguá, Rio de Janeiro - RJ - Brasil - CEP 22775-113

E-mail: marianalivramento@hotmail.com

\section{LUIS FERNANDO HOR=MIEYLL}

Doutor em Administração pelo Departamento de Administração da Universidade Federal do Rio de Janeiro (UFRJ).

Professor do Departamento de Administração da Pontifícia Universidade Católica do Rio de Janeiro (PUC-RJ). Rua Marquês de São Vicente, 225, Gávea, Rio de Janeiro - RJ - Brasil - CEP 22451-900 E-mail: hormeyll@iag.puc-rio.br

\section{LUÍS ALEXANDRE GRUBITS DE PAULA PESSÔA}

Doutor em Letras pelo Departamento de Letras da Universidade Presbiteriana Mackenzie (UPM). Professor do Instituto de Administração e Gerência da Pontifícia Universidade Católica do Rio de Janeiro (PUC-RJ). Rua Marquês de São Vicente, 225, Gávea, Rio de Janeiro - RJ - Brasil - CEP 22451-900

E-mail:lpessoa@iag.puc-rio.br 


\section{RESUMO}

$\mathrm{O}$ artigo tem como objetivo identificar valores individuais que motivam mulheres de baixa renda, mesmo vivendo com severas limitações financeiras, a comprar produtos de beleza, que poderiam, à primeira vista, ser considerados itens supérfluos. O modelo de cadeia meios-fim de Gutman (I982) e os tipos de valores de Rokeach (I973) e Floch (I990) constituíram sua base conceitual. Foram conduzidas entrevistas em profundidade, empregando a técnica laddering (REYNOLD; GUTMAN, I988), com I7 mulheres de baixa renda residentes na cidade do Rio de Janeiro. As entrevistas também foram interpretadas com o auxílio de análises de conteúdo e de discurso. Os resultados trazem evidências de que, com o uso de produtos de beleza, as consumidoras de baixa renda buscam elevar sua autoestima, constantemente abalada pelas restrições financeiras, que as coloca em permanente situação de desvantagem. Também buscam, por meio da beleza, obter respeito de classes sociais hierarquicamente superiores, já que a aparência parece ser uma maneira eficaz para diminuir sua percepção de discriminação por serem pobres. As entrevistadas mostraram-se muito conscientes de suas limitações orçamentárias para aquisição de produtos de beleza, comprando apenas o que podem pagar. A marca dos produtos selecionados para compra surgiu como fator importante em suas escolhas, não para obter status, mas como garantia da qualidade dos produtos. Este trabalho buscou ampliar o conhecimento sobre o comportamento de consumo dos grupos sociais na base da pirâmide, examinando questões ainda pouco exploradas, como valores de sua subcultura. Sob a perspectiva gerencial, esta pesquisa propõe contribuições para a gestão do composto de marketing de empresas que pretendam atuar nesse mercado.

\section{PALAVRAS-CHAVE}

Valores e consumo; Mulheres de baixa renda; Produtos de beleza; Consumo na base da pirâmide; Consumidor em desvantagem. 


\section{INTRODUÇÃO}

Por muitos anos, o mercado constituído pelos indivíduos de baixa renda permaneceu invisível aos olhos de empresas e acadêmicos. No Brasil, com o significativo crescimento de seu potencial de consumo, ocorrido a partir de 1994 com a implantação do Plano Real (BARROS, 2006), esse segmento passou a despertar o interesse da academia (PITTA; GUESALAGA; MARSHALL, 2008; WOOD; PITTA; FRANZAK, 2008; ROCHA; SILVA, 2008) e de empresas que vislumbraram a oportunidade de lucrar atendendo a esse mercado.

Aparelhos de televisão e de DVD (CASTILHOS; ROSSI, 2009) e computadores (BARROS, 2009) são itens já presentes em lares de famílias de baixa renda, que passaram a participar mais ativamente da sociedade de consumo. Além de satisfazerem anseios, tais equipamentos propiciam status a quem os possui, uma forma de diferenciá-los de vizinhos e amigos (CASTILHOS; ROSSI, 2009).

Apesar de o poder de consumo de famílias brasileiras de baixa renda estar em ascensão, devido a aumentos reais de salários e da expansão do crédito, o restrito orçamento familiar é real e limitante. Dificuldades financeiras fazem parte da realidade de suas vidas, resultando em necessidades básicas, como habitação e alimentação, sem ser plenamente atendidas em muitos casos (SILVA; PARENTE, 2007).

Ainda assim, algumas pessoas valorizam tanto a posse de certos bens que preferem alimentar-se pior a abrir mão de itens que consideram imprescindíveis (SILVA; PARENTE, 2007). Mesmo convivendo com recursos financeiros muito limitados, direcionam parcela não desprezível de seu orçamento para a compra de itens que, à primeira vista, poderiam ser considerados supérfluos. Produtos de beleza poderiam ser avaliados como tal, mas, curiosamente, são regularmente adquiridos por consumidoras com sérias restrições financeiras.

Tal curiosidade originou o presente estudo: buscou-se identificar motivações que explicassem a compra de produtos de beleza por mulheres que, a cada decisão de consumo, vivem intensas pressões, decorrentes de seu restrito orçamento familiar.

\section{CONCEITUALIZANDO BAIXA RENDA}

Não existe consenso em relação ao que caracteriza um consumidor de baixa renda. Prahalad (2005) e Karnani (20II) consideraram a posição do indivíduo na pirâmide econômica, sendo os pobres (o que Prahalad chamou de "base da pirâmide") aqueles com renda diária igual ou inferior a US\$2,00 (renda mensal individual até $\mathrm{R} \$ \mathrm{I} 20,00)$. 
Para definir os consumidores de baixa renda, estudos conduzidos no Brasil utilizaram tanto a renda familiar mensal (com diferentes limites superiores) como a classe social na qual o indivíduo se enquadra. Por exemplo, Silva e Parente (2007) consideraram renda familiar entre dois e cinco salários mínimos (equivalendo, em 20I2, à faixa de R\$ I.244,00-R \$ 3.II0,00). Para Assad e Arruda (2006) e Motta e Casarin (2006), renda familiar inferior a quatro salários mínimos (equivalendo, em 20I2, a R\$2.488,00) caracterizaria baixa renda; Grossi, Motta e Hor-Meyll (2009) e Barbosa, Hor-Meyll e Motta (2009) consideraram renda familiar mensal até três salários mínimos (correspondendo, em 2012, a $\mathrm{R} \$$ I.866,00). Já para Mattos (2007), seriam indivíduos pertencentes às classes sociais $\mathrm{C}$ e $\mathrm{D}$.

Não havendo uma clara definição do conceito, optou-se, neste estudo, por considerar como de baixa renda famílias com orçamento mensal igual ou inferior a quatro salários mínimos.

\section{MULHERES DE BAIXA RENDA E CONSUMO}

No Brasil, as mulheres têm papel fundamental nas decisões de consumo das famílias de baixa renda. Principais responsáveis pelas decisões de como empregar os parcos recursos financeiros da família, elas são 29 milhões, tendo entre I8 e 49 anos (BCG, 2002). A elas cabe o papel de economizar com compras, comprar as miudezas do dia a dia e esticar o orçamento com a receita de trabalhos avulsos que eventualmente consigam (BCG, 2002). Suas principais preocupações são a estabilidade financeira, a saúde, a família e o trabalho, mas buscam melhor qualidade de vida (63\%) e bem-estar (59\%) e procuram cuidar de sua beleza e estética (57\%). Exercitar-se em academias de ginástica, frequentar massagistas e salões de cabeleireiro e praticar esportes são atividades que gostariam de incluir em sua rotina (ABRIL; IBOPE, 2009).

A marca tem grande importância para os consumidores menos favorecidos, servindo não apenas como sinalizador de qualidade, mas também de hierarquia social (ROCHA; SILVA, 2008). As mulheres de baixa renda valorizam marcas conhecidas, priorizando as que estão em promoção, portanto, com menor preço. Para mostrar status e aumentar a autoestima, buscam ter em casa produtos de marcas reconhecidas (ISSA JR., 2004). Entretanto, apenas para algumas categorias de produtos a marca é fundamental: itens de higiene pessoal, produtos de higiene doméstica, acessórios, vestuário, alimentos e bebidas. A categoria em que a marca parece menos importar refere-se a atividades de lazer e cultura (ABRIL; IBOPE, 2009). 
Maquiagem é um item importante quando querem se sentir bonitas. Mesmo as que afirmam não gostar de maquiar-se consideram batom, lápis e base como produtos básicos. Avon e Natura são as duas marcas de cosméticos mais citadas, por serem fortes anunciantes e terem penetração no mercado graças às suas forças de vendas. Marcas internacionais consagradas não são lembradas por não serem acessíveis a seu padrão de renda (JORDÃO, 2008).

Apesar de parecer que as mulheres de baixa renda constituem um grupo homogêneo, uma observação mais detalhada revela subgrupos (IBOPE SOLUTION apud ISSA JR., 2004):

- "Eu me amo": com idade entre 25 e 34 anos, esbanjam autoestima e vaidade. Sem medo de expressar seu desejo pelo novo para serem socialmente aceitas, buscam o prazer sem culpa, gostam de novidades e de vestir-se bem, de testar novas marcas e produtos.

- “Eu acredito": elas são vaidosas e agem por impulso na hora de comprar. Têm forte senso de harmonia e se consideram socialmente aceitas.

- "Eu sobrevivo": são mulheres acima de 35 anos, casadas e responsáveis pelo sustento da família. Suas maiores preocupações são o crescimento e o sucesso dos filhos. Não valorizam o cuidado com o próprio corpo e têm baixa autoestima.

- "Eu vou conseguir": com idade entre i8 e 24 anos, um dos seus principais objetivos é estudar. Valorizam o conhecimento e a leitura, buscando no sucesso profissional a chave para a integração e a aceitação social.

- "Eu não aceito": são mulheres insatisfeitas e sem esperança na vida. Por desilusão, desconfiam das instituições e da própria família. Na hora das compras, agem de forma inconsequente e muitas vezes por impulso.

“Eu me amo”, “eu vou conseguir" e "eu acredito” são os segmentos com maior potencial de ascensão social, compostos por mulheres satisfeitas com a vida e otimistas quanto ao futuro, além de terem boa aparência e o hábito de cuidar do corpo. Compram mais produtos de primeira necessidade, são ligadas à tecnologia e a produtos supérfluos, valorizam qualidade e são leais às marcas de que gostam (ISSA JR., 2004). No entanto, suas restrições orçamentárias são reais: responsáveis pela decisão de gastos familiares, para não perderem o controle do orçamento, fazem pesquisa prévia de preços que baseia a lista de compras, consultando folhetos de ofertas e anúncios, ou visitando pontos de venda, conseguindo reduzir em até I2\% os gastos mensais com alimentação, higiene e limpeza (BCG, 2002).

Aproximadamente $65 \%$ do gasto mensal de famílias de baixa renda estão previamente comprometidos com alimentação (48\%) e moradia (I7\%), restando 
pouco para educação, lazer e saúde (BOSTON CONSULTING GROUP, 2002). Apesar da considerável parcela do orçamento comprometida com a alimentação, em sua maioria as famílias estão insatisfeitas com a qualidade e com a quantidade de alimentos que consomem (SILVA; PARENTE, 2007).

Para quem convive de perto com a possibilidade da falta de comida, todo alimento é considerado uma benção, algo sagrado. Ainda assim, há insatisfação com a repetição da rotina alimentar. Quando questionadas sobre que tipo de comida gostariam de substituir, as mulheres de baixa renda declararam que gostariam de "coisas boas, de rico", como lasanha e empadão (CASOTTI; SUAREZ; DELIZA, 2009).

A limitação de renda e as situações adversas inerentes a ela provocam a sensação de falta de poder (FUSTAINO; YAMAMOTO, 2009). Estudos conduzidos no Brasil identificaram estados estáveis de baixo poder e de baixa autoestima em consumidores de baixa renda, associados ao sentimento de inferioridade e de exclusão social causado pela limitação de recursos financeiros (CHAUVEL; SUAREZ, 2009; FUSTAINO; YAMAMOTO, 2009; BARBOSA; HOR-MEYLL; MOTTA, 2009).

Pessoas de baixa renda sentem-se inferiorizadas por serem conscientes dos valores da sociedade, que associa prestígio à situação econômica do indivíduo. A falta de recursos econômicos, principalmente quando relacionada ao status social, parece conduzir ao consumo de produtos (e serviços) que reduzam a sensação de discriminação social (RUCKER; GALINSKY, 2008): as pessoas de baixa renda adquirem e consomem, com frequência, produtos não necessários para a sua subsistência (PRAHALAD, 2005), além de valorizarem e serem leais a marcas relacionadas a status como forma de se destacarem em seu ambiente social (PRAHALAD, 2005; BARROS, 2007; CHAUVEL; MATTOS, 2008; GROSSI; MOTTA; HOR-MEYLL, 2009; DANTAS et al., 20I0).

O consumo torna-se, dessa forma, uma maneira de combater o sentimento de exclusão social, por possibilitar a exposição, por meios simbólicos, da capacidade de compra do indivíduo e da redução da diferença social (GROSSI; MOTTA; HOR-MEYLL, 2009; DANTAS, 20I0).

\section{BELEZA E STATUS SOCIAL}

$\mathrm{Na}$ interação social, a aparência física e a identidade sexual são as características mais óbvias e acessíveis do indivíduo (DION; BERSCHEID, I972). Belo é algo que agrada e está associado ao bom (ECO, 2004; DION; BERSCHEID, I972; EAGLY et al., I99I), enquanto o feio é associado ao fraco, sem objetivo, irresponsável com o próprio corpo (NOVAES; VILHENA, 2003). Nas narrativas 
folclóricas, príncipes, princesas, fadas e heróis são considerados verdadeiros e justos e são bonitos, mas personagens maldosos, como bruxas, feiticeiras e vilões, são feios (TEIXEIRA, 200I).

O mundo é mais prazeroso para os belos, pelas vantagens sociais que obtêm decorrentes de sua beleza, que influencia na interação social - os belos têm mais possibilidade de obter sucesso, de fazer com que outros concordem com eles (ETCOFF, 2000; TEIXEIRA, 200I) e de influenciar terceiros (WEBSTER; DRISKELL, I983). As pessoas gostam de agradar aos indivíduos que têm boa aparência, deles se aproximando, deixando-se persuadir e a eles confidenciando informações. Em geral, assumem que indivíduos de boa aparência têm mais qualidades positivas do que outras pessoas menos aquinhoadas em atributos físicos (ETCOFF, 2000).

A associação beleza-feminilidade parece tão antiga quanto a civilização (VILHENA; MEDEIROS; NOVAES, 2005). Historicamente, as mulheres sempre se preocuparam com a beleza, mas hoje são responsáveis por ela: de um dever social (se você conseguir, melhor), a beleza tornou-se um dever moral (se você quiser, consegue).

O fracasso não está mais ligado a uma impossibilidade física, mas à incapacidade individual: em passado não muito distante, quando uma mulher não era bela, a culpada era a natureza. Hoje, a responsabilidade é da própria mulher por sua negligência (NOVAES; VILHENA, 2003), já que a beleza deixou de ser apenas um dom natural - pode ser comprada e conquistada (LIPOVETSKY, I989). As pessoas investem tanto em beleza e arriscam-se tanto por ela que parece que suas vidas dela dependem (ETCOFF, 2000).

Para os homens, a boa aparência associa-se a fatores objetivos, como seu papel perante a sociedade. Para as mulheres, no entanto, a aparência tem relação direta com conquistas subjetivas, como felicidades amorosa, familiar e sexual. No universo masculino, a falta de tempo atribuída ao ritmo acelerado da vida profissional funciona como desculpa aceitável. Para a mulher, é como se não houvesse justificativa plausível para não ser bela: não ter vaidade é uma depreciação moral (NOVAES; VILHENA, 2003).

As pessoas julgam a beleza como se existisse, em suas mentes, um padrão ideal (ETCOFF, 2000). Entretanto, padrões estéticos estão ligados a épocas e culturas (ECO, 2004; BOUZÓN, 2004; NOVAES; VILHENA, 2003).

O padrão ocidental atual prega a juventude (GOLDENBERG, 2007), socialmente valorizada como o estado ideal de ser e condição necessária para a beleza (VANZELLOTTI, 2007; TEIXEIRA, 200I). A mulher que nele não se enquadrar arrisca-se a ser socialmente excluída, rotulada como negligente, preguiçosa e descuidada (NOVAES; VILHENA, 2003). A fiscalização, através de olhares minuciosos, compara indivíduos e influencia sua autoestima - a impossibilidade 
de minimizar diferenças entre o padrão de beleza imposto e a realidade do espelho gera desamparo e depressão e diminui a autoestima (LEMES, 2006). As mulheres são compelidas a cuidar de seus corpos para que se sintam inseridas na sociedade (NOVAES; VILHENA, 2003; LEMES, 2006; FONTES, 2009; VILHENA; MEDEIROS; NOVAES, 2005).

Cuidar do corpo é uma forma que os indivíduos têm para enfrentar julgamentos e expectativas sociais. A beleza corporal dá retorno, e, por essa recompensa, as pessoas buscam e realizam diferentes tipos de procedimentos. Por mais altos que sejam os custos emocionais, físicos e financeiros decorrentes, a relação custo-benefício é positiva, já que as recompensas emocionais, sociais e materiais, proporcionadas pela beleza, são ainda maiores (TEIXEIRA, 200I). Produtos de beleza deixaram de ser privilégio de poucas classes sociais (LIPOVETSKY, I989): cosméticos deixaram de ser "luxo" para se tornarem artigo regular de consumo. O uso de produtos e serviços que tornem as mulheres mais belas não só as ajuda a construir a sua feminilidade, mas também a sua própria aceitação social (MACHADO; PEREIRA, 20IO).

\section{VALORES}

Os valores - e seu papel na orientação da vida dos indivíduos, das organizações e das sociedades - têm sido estudados sob a perspectiva de diferentes áreas do saber. Enquanto, na economia, o valor está inserido no contexto da troca (RICHINS, I994), na abordagem de marketing o conceito de valor não está limitado apenas ao aspecto econômico, abrangendo percepções e escolhas.

Ainda que se observe a predominância de estudos de natureza psicológica, outras possibilidades, com destaque para abordagens interdisciplinares, podem vir a ser descortinadas (TEIXEIRA; TORRES, 2009). Para tal, neste artigo procurou-se conciliar a abordagem da cadeia meios-fim (GUTMAN, I982) com a semiótica discursiva de linha francesa (GREIMAS, I983).

Valores são fruto da sociedade em que o consumidor vive, das instituições com que tem contato, e de sua personalidade (VELUDO-DE-OLIVEIRA; IKEDA, 2005).Valores pessoais influenciam o comportamento de consumo, apesar de os consumidores não perceberem tal fato (SCOTT; LAMONT, I973; CLAWSON; VINSON, I978; GUTMAN, I982).

Rokeach (I973, p. 5) definiu valores humanos como "crenças estáveis de que um modo de conduta ou estado final de existência específico seja, pessoal ou socialmente, preferível a outro modo de conduta ou estado de existência oposto ou alternativo" e os categorizou como valores terminais, que representam estados finais desejados pelo indivíduo, verdadeiras metas que buscam em sua vida, e valores instrumentais, que são meios para alcançar os valores terminais. 
Schwartz (I992) propôs uma definição que, como a de Rokeach (I973), considera os valores como conceitos ou crenças relacionados a estados finais de existência ou comportamentos desejados, que transcenderiam situações específicas, guiariam a seleção e a avaliação de eventos e comportamentos, e seriam ordenados por sua importância relativa. Identificou dez tipos motivacionais de valores, cada qual dando origem a um grupo de valores que, ao se correlacionarem diretamente entre si, formariam um fator. Os tipos motivacionais de valores seriam derivados das necessidades básicas, dos motivos sociais e de demandas institucionais para a sobrevivência e o bem-estar dos grupos, e poderiam ser considerados a partir de duas dimensões de ordem superior, a autopromoção versus autotranscendência e abertura à mudança versus conservadorismo (SCHWARTZ, I994).

Schwartz (I994) também testou a classificação dos valores, proposta por Rokeach (I973), em instrumentais e terminais, mas não encontrou evidências empíricas que a sustentassem, entendendo que seria consequência apenas de uma questão semântica, já que um valor pode ser interpretado como instrumental ou terminal conforme seja descrito na forma de um adjetivo (por exemplo, independente) ou na de um substantivo (independência).

Os valores relacionados a poder teriam como objetivo central a obtenção de prestígio e status social, e controle ou dominância sobre pessoas e recursos, como preservar a imagem pública e obter reconhecimento social (SCHWARTZ, I992).

Diversos autores relacionaram valores a produtos ou a serviços. Woodruff (I997) definiu valor para o cliente como a preferência e a avaliação dos atributos dos produtos, de seu desempenho e das consequências obtidas com seu uso, que facilitam (ou dificultam) o consumidor a alcançar seus objetivos e propósitos. O valor para o cliente vincularia atributos de produtos e seu desempenho a consequências e objetivos (valores pessoais) pretendidos com seu uso. A associação dos três fatores (atributos, consequências e valores pessoais), representando a relação entre o comportamento do consumidor e o consumo de produtos e serviços, e seus valores pessoais, serviu de base para a cadeia meios-fim de Gutman (I982).

A cultura da qual o consumidor faz parte também influencia a forma como ele avalia os atributos de um produto - membros de culturas individualistas valorizariam o significado utilitário do produto, ao passo que membros de culturas coletivistas fariam avaliação de natureza afetiva, enfatizando o significado simbólico (TORRES; ALLEN, 2009).

Sheth, Newman e Gross (I99I) classificaram atributos como funcionais, quando o produto ou serviço satisfaz seu propósito físico ou funcional; como sociais, quando satisfazem a necessidade social por meio da associação a determinados segmentos demográficos, socioeconômicos ou etnográficos de uma sociedade; emocionais, quando satisfazem a necessidade de criar emoções e senti- 
mentos adequados; epistêmicos, quando o produto ou serviço satisfaz a necessidade humana de aprender ou conhecer algo novo; e como situacionais, quando satisfazem necessidades situacionais ou contingentes em determinado lugar ou tempo.

Holbrook (I999) considerou valor como um constructo multidimensional, identificando três dimensões:

- Finalidade: o valor intrínseco tem um fim em si próprio, relativo às experiências do produto em si; e o valor extrínseco está associado à funcionalidade e utilidade, relacionado à experiência proporcionada.

- Orientação: o valor é auto-orientado quando o consumidor usufrui o produto em benefício próprio, ao passo que o valor orientado para outros depende da influência que o uso de um produto gera em terceiros.

- Interatividade: o valor é ativo quando proporciona a manipulação física ou mental de um objeto pelo consumidor, sendo reativo quando a interação do consumidor com o objeto é limitada.

De modo geral, os modelos de mediação pelos atributos, como a cadeia meios-fim (GUTMAN, I982), consideram que os valores influenciam a importância que o consumidor dá aos atributos de um produto ou serviço que, por sua vez, orientam sua avaliação e compra (GUTMAN, I982; SCOTT, LAMONT, I973). Embora os consumidores possam avaliar produtos por meio de cada um de seus atributos tangíveis, os intangíveis talvez sejam avaliados de forma holística (HOLBROOK, MOORE, I98I; McCRACKEN, I986). Essa argumentação constituiu base para a proposta do modelo de abordagem pelo significado do produto (product meaning approach) de Allen e Ng (1999). Entretanto, a abordagem da mediação pelos atributos é a mais amplamente aceita e implementada (ALLEN, 2000).

A semiótica posiciona a questão dos processos de significação no núcleo do comportamento do consumidor (MICK, I986), oferecendo enfoque alternativo e complementar para a compreensão dos valores humanos. Na perspectiva da semiótica discursiva de linha francesa (ou greimasiana), discursos ou comportamentos são analisados a partir de sua organização como narrativas, sendo a narratividade entendida como uma transformação situada entre dois estados sucessivos e diferentes. Cada estado podendo ser definido como a relação entre um sujeito e um objeto, a semiótica concebe a narrativa como uma circulação de objetos e denomina "programa narrativo" sua unidade elementar, constituída de um enunciado de fazer que rege um enunciado de estado. Com efeito, na análise narrativa, um determinado sujeito - um consumidor, por exemplo - realiza uma performance que o fará entrar em estado de conjunção ou de disjunção com determinado objeto, sendo o valor o significado que o sujeito atribui a esse objeto (FLOCH, I985; FIORIN, 2006; GREIMAS; COURTÉS, 2008). 
Nesse quadro teórico, Floch (1985) construiu uma axiologia do consumo a partir da definição de valor de uso e de valor de base (GREIMAS, I983). Valor de base seria um dos valores que correspondem ao plano das preocupações fundamentais do ser e cuja busca sustenta a vida, dando sentido a múltiplos programas secundários de ação, mais superficiais ou mais práticos. Na propaganda de automóveis franceses na década de i980, por exemplo, Floch (1985) observou que, quando o carro representa a identidade de seu condutor, seu estatuto social ou sua virilidade, ou quando é a própria figuração da vida ou da beleza, estaria investido de um valor de base. Quando a propaganda exalta a dirigibilidade ou a confiabilidade, valorizando como meio de transporte, o veículo está investido de valores de uso.

Floch (I985) constatou que, nas campanhas publicitárias, a dupla funcionalidade do automóvel, apesar de implícita, dá-se constantemente por oposição, como se o sujeito precisasse, a priori, escolher entre a "utilização" (no sentido de valor de uso), que corresponde às necessidades, e a "fruição" (no sentido de valor de base), relacionada a desejos. Para a teoria semiótica, o programa de uso é apenas um pressuposto para a realização do programa de base (GREIMAS; COURTÉS, 2008), aproximando-se da definição de Rokeach (I973), em que valores instrumentais são meios para alcançar valores terminais. Entretanto, nas situações cotidianas, grande parte das ações e dos estados de alma de um sujeito, bem como seu comportamento de consumo, vem "dessa transformação de uma implicação entre valores de uso e valores de base em uma contrariedade, e da procura mais ou menos sistemática de uma conciliação mítica entre esses valores, entendidos, a partir daí, como contrários" (FLOCH, I985, p. I28).

Floch (I985) propôs então um quadrado semiótico (GREIMAS; COURTÉS, 2008), baseado em quatro tipos de valorização (Figura I).

\section{FigURA I}

\section{TIPOS DE VALORIZAÇÃO}

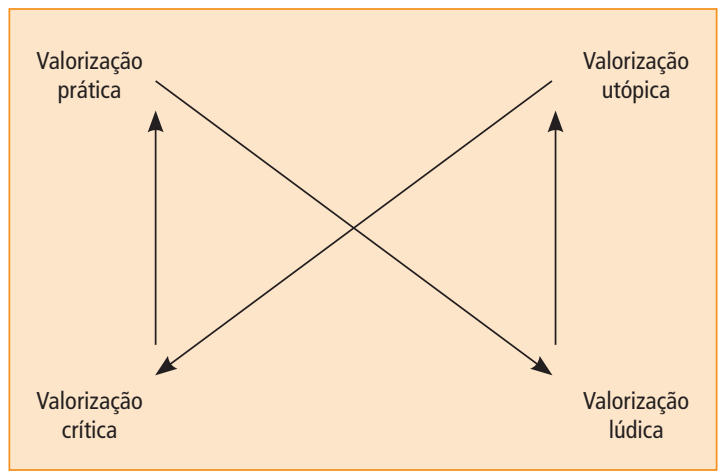

Fonte: Elaborada pelos autores com base em Floch (I990). 
A valorização prática (valores utilitários) corresponde aos valores de uso concebidos como contrários dos valores de base; a valorização utópica (valores existenciais) corresponde aos valores de base concebidos como contrários dos valores de uso (nesse contexto, o termo utópico não é aplicado no sentido de "ilusório", mas como "visão de um objetivo" ou daquilo que é desejado); a valorização lúdica (valores lúdicos) corresponde à negação dos valores utilitários (o termo "lúdico", aqui, tem o sentido de "atividade livre por excelência"); e a valorização crítica (valores críticos) corresponde à negação dos valores existenciais, utópicos. A valorização crítica refere-se, portanto, à lógica do exame, da distância (que permite a objetividade) e do cálculo econômico ou técnico, a partir, por exemplo, da avaliação das relações qualidade/preço e custo/benefício.

As relações entre os valores que definem o quadrado semiótico da axiologia do consumo de Floch (I985) ora são exclusivas, ora compatíveis. Na análise do discurso, deve-se observar, portanto, que o quadrado semiótico não é apenas um modelo que indica as posições relativas dos termos em relação aos outros, mas cumpre também a função dinâmica de apresentar a passagem de uma posição à outra (BERTRAND, 2003).

\section{A CADEIA MEIOS-FIM}

Baseados em Rokeach (I973), Vinson, Scott e Lamont (I977) interpretaram o sistema atitude-valor do consumidor por meio de uma estrutura hierárquica que associa a avaliação que ele faz do produto (seus atributos) aos valores de domínio específico e, em seguida, aos valores globais (VELUDO-DE-OLIVEIRA; IKEDA, 2005). A cadeia de benefícios pode ser considerada uma associação de benefícios, emocionais e psicológicos, a produtos ou a seus atributos. Uma cadeia de benefícios começa com a descrição de um produto incluindo atributos específicos. A partir daí, o consumidor associa benefícios (funcionais) aos atributos, que são, então, associados a aspectos emocionais que representam consequências obtidas com o uso do produto (YOUNG; FEIGIN, I975)

Gutman (I982) baseou-se na orientação de valores proposta por Rokeach (I973), na centralidade das crenças de Vinson, Scott e Lamont (I977) e no modelo das cadeias meios-fim de Howard (I977) para propor um modelo cujo aspecto central é o fato de consumidores escolherem ações que produzam consequências desejadas e minimizem consequências indesejadas. De acordo com Rokeach (I973, p. 6I), "Sugere-se que valores oferecem consequências com valência positiva ou negativa; assim, a ligação valores-consequências é uma das ligações críticas no modelo". 
Howard (I977) definiu valores terminais e instrumentais da mesma forma que Rokeach (I973). Entretanto, o modelo de Gutman (I982) difere do de Howard (I977) pelo fato de não ter adotado o conceito de valores instrumentais.

Os meios seriam objetos (produtos) ou atividades (correr, ler) nas quais as pessoas se engajam, e fins seriam estados de existência valorados (felicidade, segurança e realização). O modelo explicaria como a escolha de um produto ou serviço leva o consumidor a alcançar o estado final desejado (GUTMAN, I982): baseado na sequência atributo-consequência-valor, o consumidor associa conhecimento sobre atributos do produto a conhecimento sobre consequências de seu uso e, finalmente, a valores individuais.

As consequências representam o nível intermediário da cadeia, a ponte entre atributos dos produtos e valores do consumidor. Gutman (I982) as definiu como o resultado (físico ou psicológico) esperado do consumo do produto ou do serviço, que pode ser desejável (benefício) ou indesejável.

Os consumidores aprendem a desejar determinadas consequências de acordo com as possibilidades de que estas os ajudem a atingir seus objetivos finais (WOODRUFF, I997). Para Gutman (I982), o aspecto central da cadeia meios-fim é o fato de os consumidores buscarem tomar decisões que produzam consequências desejadas e minimizem consequências indesejáveis. Para isso, devem escolher produtos que tenham os atributos necessários para atingir as consequências buscadas.

Consequências podem ser de natureza fisiológica (saciar a fome, sede ou outra necessidade fisiológica), psicológica (autoestima, por exemplo) ou sociológica (interação social). Podem ser diretas, quando vêm diretamente do produto consumido ou do ato do consumo, ou indiretas, quando outras pessoas reagem ao consumo, favorável ou desfavoravelmente (GUTMAN, I982). O sistema de valores do consumidor estrutura sua busca por consequências que venham a suprir suas necessidades e determina se são desejáveis ou indesejáveis (KAMINSKI, 2004).

\section{MÉTODO}

Reynolds e Gutman (I988) introduziram laddering nas pesquisas de marketing, um método que envolve entrevistas em profundidade usadas para compreender como os consumidores traduzem os atributos dos produtos em associações com significados a respeito de si mesmos. O método também contempla a análise e interpretação dos dados colhidos.

Inicialmente, as entrevistas levam os consumidores a mencionar os principais atributos que percebem nos produtos. Três abordagens podem ser utilizadas pelo 
entrevistador (REYNOLDS; GUTMAN, I988): a escolha entre três (triadic sorting), quando três marcas distintas são apresentadas ao entrevistado, que é solicitado a enumerar semelhanças e diferenças de duas marcas em relação à terceira; diferenças de preferência de consumo (preference consumption differences) - nesse caso, solicita-se ao entrevistado que ordene as marcas de acordo com sua preferência e indaga-se a razão de uma marca ser a preferida; e diferenças de ocasião (differences by occasion), quando se insere o entrevistado em um contexto de consumo para que ele descreva as características desse consumo.

A partir da descoberta dos principais atributos, buscam-se, na condução da entrevista, as conexões entre atributos, consequências e valores - a hierarquia de valor (GUTMAN, I982; VALLETE-FLORENCE; RAPACCHI, I99I; WOODRUFF; GARDIAL, I996), levantando-se questões como "Por que isso é importante?", "O que isso significa para você?" e "Qual é o significado de o produto ter ou não tal atributo?”. Essas perguntas são feitas repetidas vezes, até que se consiga encadear os atributos (A), as consequências (C) e, finalmente, os valores (V) (VELUDO-DE-OLIVEIRA; IKEDA, 2004), identificando a percepção do consumidor de como os níveis relacionam-se (LEÃO, 200I).

Diferentes sequências A-C-V (ladders) são identificadas nas entrevistas, quantificando-se seus elementos e relações para permitir a construção da representação gráfica de suas conexões no mapa hierárquico de valores (REYNOLDS; GUTMAN, I988).

Para favorecer a redundância das respostas, assim facilitando a categorização dos elementos das ladders, conduziu-se inicialmente uma entrevista em grupo, com seis mulheres, seguindo recomendação de Veludo-de-Oliveira, Ikeda e Campomar (2006b) para que sejam utilizados grupos de pessoas nos passos de obtenção de dados. As entrevistadas foram solicitadas a debater sobre o consumo de produtos de beleza (técnica de diferenças de ocasião) e estimuladas a descrever atributos desses produtos. A partir daí, perguntas como "Por que isso é importante?" e "O que isso significa para você?” foram formuladas.

Os ladders obtidos na entrevista em grupo e nas II entrevistas individuais subsequentes foram bastante homogêneos, atendendo à recomendação de Veludo-de-Oliveira e Ikeda (2004) e Veludo-de-Oliveira, Ikeda e Campomar (2006b). Dessa forma, as entrevistas em grupo também foram incluídas na análise.

Duas entrevistas adicionais não acrescentaram novas informações, sugerindo ter sido atingida a saturação. Assim, foram considerados para a análise os relatos de I7 entrevistadas (todas residentes na cidade do Rio de Janeiro, com renda igual ou inferior a quatro salários mínimos), que foram gravados e transcritos. O perfil das entrevistadas está apresentado no Quadro I. 


\section{QUADRO I}

PERFIL DAS ENTREVISTADAS

\begin{tabular}{|c|c|c|c|c|c|}
\hline NOME & IDADE & ESTADO CIVIL & PROFISSÃO & MORA COM & PROFISSÃO DO MARIDO \\
\hline Patrícia & - & Solteira & Faxineira & 4 filhos & - \\
\hline Vilma & - & Divorciada & Faxineira & 2 filhos & - \\
\hline Fernanda & - & Casada & Faxineira & 5 filhos e marido & Entregador \\
\hline Ivonete & 41 & Casada & Faxineira & 2 filhos e marido & Segurança \\
\hline Kátia & - & Casada & Faxineira & 1 filha e marido & Aux. administrativo \\
\hline Francisca & - & Casada & Faxineira & marido & Técnico da Light \\
\hline Valéria & 40 & Divorciada & Faxineira & sozinha & - \\
\hline Marluce & 37 & Casada & Copeira & 1 filho e marido & Pedreiro \\
\hline Ana Paula & 29 & Solteira & Faxineira & sozinha & - \\
\hline Nilce & 35 & Casada & Digitadora & 1 filho e marido & Pedreiro \\
\hline Agnes & 19 & Solteira & Segurança & mãe & - \\
\hline Vanessa & 23 & Casada & Faxineira & 2 filhos e marido & Entregador \\
\hline Maria & 38 & Casada & Faxineira & 5 netos e marido & Pedreiro \\
\hline Kátia & 38 & Casada & Digitadora & 2 filhos e marido & Ascensorista \\
\hline Ana Luisa & 32 & Divorciada & Atendente & 1 filho & - \\
\hline Tatiana & 26 & Divorciada & Atendente & 1 filho & - \\
\hline Matilde & 32 & Casada & Manicure & 1 filho e marido & Aux. contabilidade \\
\hline
\end{tabular}

Fonte: Elaborado pelos autores.

\section{ANÁLISE dOS RESULtAdOS}

A interpretação dos dados dividiu-se em quatro etapas (REYNOLDS; GUTMAN, I988):

- Análise de conteúdo por meio de leitura minuciosa, identificando-se orações ou palavras-chave. Aquelas com o mesmo sentido foram alocadas sob 
a mesma oração ou palavra-chave e, então, classificadas como atributos (A), consequências (C) ou valores (V). Com isso, foram geradas sequências A-C-V e seus elementos codificados com números crescentes, representando atributos, consequências e valores.

- Desenvolvimento da matriz de implicação, em que os elementos codificados foram dispostos, por meio de seus códigos, em linhas e colunas. Pela análise das ladders de cada entrevistada, verificaram-se quantas vezes um elemento levava a outro e o tipo de relação entre eles (diretas, quando adjacentes, ou indiretas, quando existissem outros elementos interpostos).

- Construção do mapa hierárquico de valor, inter-relacionando as cadeias significativas, a fim de facilitar sua interpretação. Apenas as relações relevantes entre atributos, consequências e valores foram identificadas, a partir de um ponto de corte (o mínimo de vezes em que as relações diretas e indiretas apareceram).

- Determinação das orientações de percepção dominantes a partir do mapa hierárquico de valor, identificando-se quais cadeias meios-fim mais contribuíram para o resultado final (cadeias dominantes).

\section{QUADRO 2}

ELEMENTOS IDENTIFICADOS

\begin{tabular}{clcl}
\hline & & ATRIBUTOS & \\
\hline CÓDIGO & ATRIBUTOS CONCRETOS & CÓDIGO & ATRIBUTOS ABSTRATOS \\
\hline 1 & Preço baixo & 4 & Qualidade \\
\hline 2 & Preço alto & 5 & Não dá alergia \\
\hline 3 & Grande quantidade (embalagem) & - & - \\
\hline
\end{tabular}

\begin{tabular}{clcl}
\hline \multicolumn{5}{c}{ CONSEQUENCIAS } \\
\hline CÓDIGO & CONSEQUÊNCIAS FUNCIONAIS & CÓDIGO & CONSEQUÊNCIAS PSICOLÓGICAS \\
\hline 6 & Evita desperdício & 8 & Sentir-se mais bonita \\
\hline 7 & Dá melhores resultados & 9 & Status \\
\hline- & - & 10 & Sentir-se desejada pelos homens \\
\hline- & - & 11 & Sentir-se desejada pelo parceiro \\
\hline
\end{tabular}

(continua) 
QUADRO 2 (CONCLUSÃo)

ELEMENTOS IDENTIFICADOS

\begin{tabular}{|c|c|c|c|}
\hline \multicolumn{4}{|c|}{ CONSEQUÊNCIAS } \\
\hline CÓDIGO & CONSEQUENNCIAS FUNCIONAIS & CÓDIGO & CONSEQUÊNCIAS PSICOLÓGICAS \\
\hline- & - & 12 & Ser notada \\
\hline- & - & 13 & $\begin{array}{l}\text { Diferenciar-se das mulheres de sua } \\
\text { classe }\end{array}$ \\
\hline- & - & 14 & $\begin{array}{l}\text { Diminuir a percepção da diferença } \\
\text { social }\end{array}$ \\
\hline \multicolumn{4}{|c|}{ VALORES } \\
\hline CÓDIGO & & CÓDIGO & \\
\hline 15 & Reconhecimento social & 16 & Autoestima \\
\hline - & - & 17 & Ser respeitada \\
\hline
\end{tabular}

Fonte: Elaborado pelos autores.

Atributos, consequências e valores foram codificados a partir do modelo A-C-V, classificados como atributos concretos e abstratos, consequências funcionais e psicológicas e valores (GUTMAN, I982; REYNOLDS; GUTMAN, I988). Os elementos estão apresentados no Quadro 2.

Foram identificados cinco atributos (três concretos e dois abstratos). Antes das entrevistas, acreditava-se poder captar número maior de atributos, entretanto a diversidade de produtos de beleza (capilares, faciais, corporais etc.) pode ter dificultado sua identificação pelas entrevistadas.

O atributo preço baixo estava relacionado a produtos acessíveis ao orçamento das entrevistadas (a maioria da marca Avon) que não exigem sacrifícios para sua aquisição. Foram considerados caros produtos que forçariam as compradoras a adaptar sua forma de pagamento ao orçamento ou a rever seus gastos mensais. Em sua maioria, são da marca Natura, considerada sonho de consumo pelas entrevistadas. A quantidade do produto contida na embalagem foi o último atributo concreto que surgiu das entrevistas.

Os atributos abstratos resumiram-se à qualidade percebida e ao fato de o produto não provocar alergia. Qualidade é um atributo que merece atenção especial, buscado por todas as entrevistadas, independentemente do preço do produto. Sua avaliação envolvia características da embalagem, durabilidade, facilidade e 
praticidade de uso. Como a maioria das compras é feita por meio de consultoras (marcas Avon e Natura), o tempo de entrega também foi avaliado como envolvido na avaliação de qualidade.

As consequências funcionais identificadas foram "evitar desperdício" e "dar melhores resultados". Quando as entrevistadas relatavam a necessidade de sempre comprar um produto de qualidade, já que limitações financeiras impediriam a recompra no caso de suas expectativas não serem atendidas, sempre se referiam a "evitar desperdício". "Dar melhores resultados" significa o produto atender à expectativa gerada por comunicação promocional do fabricante, pela marca ou por meio de indicação de terceiros.

Sentir-se mais bonita foi a primeira consequência psicológica identificada. Quando perguntadas sobre preocupação com beleza, na maioria das vezes foi a primeira a surgir: as entrevistadas diziam que, ao olhar no espelho, sentiam-se confiantes em si próprias.

Status foi interpretado como o prestígio social obtido por meio do uso do produto, seja por comprar e utilizar marcas específicas, seja pelo efeito alcançado com utilização de um produto de beleza.

Sentir-se desejada pelos homens seria despertar o olhar e a atração de homens que não o parceiro; sentir-se desejada pelo marido ou pelo namorado seria despertar o olhar e a atração de seu parceiro. As duas consequências foram consideradas separadamente, já que ficou evidente que mesmo as comprometidas gostariam de despertar a atenção do sexo oposto.

Ser vista parece estar relacionado a ser percebida por terceiros, especificamente por outras mulheres. Essa consequência não surgiu de forma espontânea nas primeiras etapas das entrevistas. Entretanto, quando as entrevistadas sentiram-se mais à vontade, diversas afirmaram que "a maioria das mulheres se arruma para ser notada por outras mulheres".

Diferenciar-se (pela beleza) de outras mulheres da mesma classe socioeconômica parece estar relacionado ao uso de marcas consideradas caras ou ao resultado estético obtido com seu uso. A percepção de diferença entre classes sociais, segundo as entrevistadas, estaria diretamente relacionada à aparência. A beleza advinda do uso de produtos, portanto, diminuiria possíveis preconceitos, existentes ou percebidos, relacionados a seu status social.

Os valores identificados foram autoestima, reconhecimento social e sentir-se respeitada. Apesar de reconhecimento social poder ser considerado como consequência psicológica, preferiu-se interpretar como um valor, assim como o fizeram Veludo-de-Oliveira e Ikeda (2006). A autoestima é o sentimento positivo da mulher em relação a si própria. A consumidora de produtos de beleza aprecia-se como mulher e sente-se bem com sua autoimagem. Ser respeitada está relacionado à busca pela admiração dos outros. 


\section{FIGURA 2}

\section{MAPA HIERÁRQUICO DE VALOR}

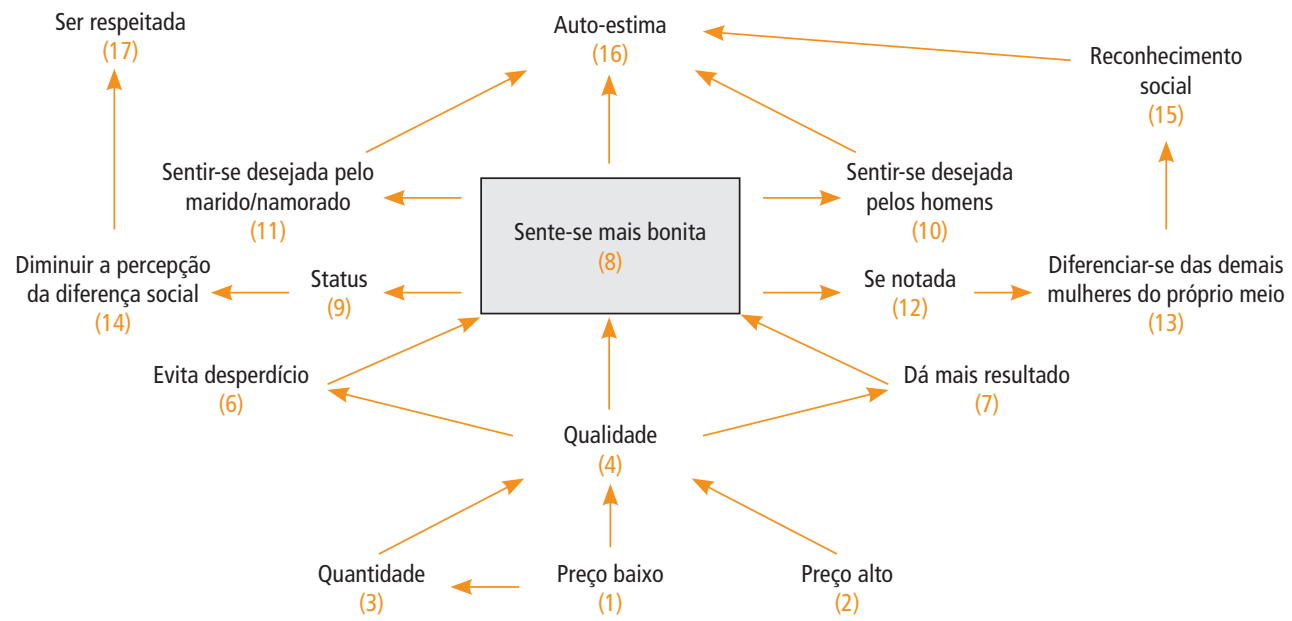

Fonte: Elaborada pelos autores.

Uma vez identificadas, as orações representativas dos elementos da cadeia meios-fim foram numeradas em ordem crescente a partir dos atributos. Uma tabela montada com todos os ladders de cada entrevistada serviu como base para a construção da matriz de implicação (LEÃO, 200I) e do mapa hierárquico de valor (Figura 2).

A autoestima surgiu como o valor mais buscado por meio do uso de produtos de beleza. Os atributos abstratos e as consequências sugerem que o aumento da autoestima dá-se a partir de três motivos:

- A mulher fica satisfeita com a sua imagem. Uma eventual diferença entre como o indivíduo é (seu "eu" real) e como gostaria de ser (o ideal definido pela sociedade) gera insatisfação e consequente redução da autoestima (BIZMAN; YINON, 2004). A importância da beleza é tão significativa na vida de uma mulher que a insatisfação em relação à autoimagem pode ter forte efeito negativo sobre a autoestima (QUEIROZ; OTTA, 2000). No caso de mulheres de baixa renda, as constantes restrições impostas por sua condição financeira colocam-nas em permanente situação de desvantagem, reduzindo ainda mais sua autoestima (RUCKER; GALINSKY, 2008), que poderá ser restabelecida por meio do consumo de produtos que as aproximem do ideal de beleza (uma forma de consumo compensatório).

- A mulher se sente desejada pelo parceiro e pelos homens. Beleza e atração estão relacionadas, o preconceito e a discriminação sofridos por mulheres consi- 
deradas feias são causados pela ausência de desejo dos homens (VILHENA; MEDEIROS; NOVAES, 2005), portanto, a atração de olhares masculinos parece aumentar a autoestima: "Quando eu faço aquela maquiagem, não tem para ninguém... todos os homens no trem me olham... É assim que eu gosto de me sentir... é assim que meu dia começa bem [...]" (Ana Paula).

- A mulher é notada por outras mulheres e reconhecida socialmente. Indivíduos mais pobres estão sujeitos a uma posição dominada na composição de classes sociais, construindo uma visão predominantemente hierárquica da sociedade (BARROS, 2006). Nessa hierarquia, a submissão das classes mais baixas às superiores, juntamente com barreiras sociais muitas vezes intransponíveis, faz com que cresça o desejo de distinção intraclasse (CASTILHOS; ROSSI, 2009). A aparência e a imagem dos indivíduos parecem ser importantes formas de diferenciação dentro de sua própria classe social. A beleza de uma mulher, muitas vezes obtida com o uso de maquiagem e produtos para os cabelos, é uma forma de diferenciá-la em seu próprio meio: "Eu me arrumo para mim e pros homens também... mas na verdade, eu quero mais é chamar atenção das outras mulheres! Quero que todas me olhem e me invejem!" (Valéria). A admiração de outras mulheres e o consequente reconhecimento social são alcançados a partir do resultado obtido com o uso do produto, independentemente de preço ou marca.

O sentimento de tratamento discriminatório, consequência da posição social, está presente no dia a dia das mulheres de baixa renda. Essa percepção de desigualdade e o desejo de ter o respeito da sociedade foram observados também por Chauvel e Suarez (2009). Muitas vezes, tal sentimento de discriminação e de falta de respeito dita o comportamento das consumidoras:

Quando a farmácia vai receber visita de gente importante, eu sempre me arrumo mais... capricho mais na maquiagem e no cabelo... porque você sabe... quando a gente tá com uniforme, com uma bandeja na mão servindo cafezinho, as pessoas costumam olhar diferente para gente [...] (Marluce).

O bom atendimento e a atenção dada ao cliente são fatores avaliados pelos consumidores de baixa renda na escolha do local das compras, seja um supermercado (PARENTE; BARKI; KATO, 2005), sejam lojas de produtos eletrônicos (BARROS; ROCHA, 2009), ou mesmo para a compra de cartões de recarga do telefone celular (BARBOSA; HOR-MEYLL; MOTTA, 2009). Cuidados com a beleza surgem como uma estratégia utilizada para disfarçar a posição social e assim obter respeito da sociedade. 


\subsection{RELAÇÃO PREÇO VERSUS QUALIDADE}

Na sequência das ladders, um aspecto chama a atenção: das 6I ladders, 43 começam com preço baixo (atributo concreto I) e I8 começam com preço alto (atributo concreto 2), sugerindo o quanto o preço pode ser significativo na compra de produtos de beleza. Das 43 ladders iniciadas com o atributo preço baixo, oito têm ligação indireta, e 35, ligação direta com qualidade (atributo abstrato), o que permite supor que as consumidoras entrevistadas buscam equilíbrio entre preço e qualidade na hora da compra de produtos de beleza. Tal equilíbrio não se limita apenas a produtos de beleza: na compra de produtos alimentícios, o peso dado à qualidade pode representar $62 \%$ do total, e, no caso de produtos de limpeza e higiene pessoal, essa porcentagem pode chegar a 69\% (BCG, 2002).

O comentário da Nilce ilustra com clareza a busca pelo binômio preço-qualidade: "é... tem que usar o barato mas com bom resultado... porque se eu for comprar o barato sem ter resultado, não adianta... e o caro também não, porque vou acabar me endividando toda". Quando mulheres de baixa renda compram produtos de beleza caros, o orçamento mensal pode ser abalado, comprometendo itens básicos como a alimentação. Por isso, mostraram-se muito conscientes em relação ao que podem pagar. Além disso, produtos mais baratos podem tornar-se fontes de problemas: elas ficarão insatisfeitas caso o resultado obtido seja aquém do esperado, já que, por não terem recursos para refazer compras equivocadas, terão que utilizar o produto até que termine.

\section{2 IMPORTÂNCIA DE MARCAS}

Os consumidores de baixa renda são muito conscientes em relação a marcas, que são sinalizadoras de qualidade e de hierarquia social (RUCKER; GALINSKY, 2008; ROCHA; SILVA, 2008). Avon e Natura foram as mais citadas, confirmando a descoberta de Jordão (2008). Ambas as marcas foram consideradas tradicionais, algo positivo, já que as mulheres entrevistadas revelaram aversão à experimentação de novas marcas que talvez não viessem a satisfazer suas necessidades (RANGAN et al., 2007).

A maioria das entrevistadas declarou utilizar produtos Avon, com preço considerado dentro de suas possibilidades financeiras, expressando satisfação com o resultado obtido. Natura foi considerada marca cara, que poucas poderiam adquirir. No entanto, quando questionadas sobre a preferência de compra entre as duas marcas, a maioria preferiria comprar Natura, se seu poder aquisitivo permitisse. Parece que percebem Avon como "marca de pertencimento", que permite que se sintam inseridas no consumo (BARROS; ROCHA, 2009). Natura seria a marca de desejo, um meio de distinção social (LEÃO; MELLO, 2008). No entanto, as 
entrevistadas mostraram-se bastante conscientes quanto à sua realidade financeira, preferindo manter controlado seu orçamento a buscar mais destaque social comprando uma marca de prestígio. Esse comportamento consciente não parece ocorrer para todas as categorias de produtos (BARROS; ROCHA, 2009). No caso de produtos de beleza, a marca parece ser importante como garantia de qualidade e dos resultados a serem obtidos, mas não necessariamente como fonte de status.

\subsection{UMA LEITURA SEMIÓTICA}

Para evitar uma análise simplista dos resultados (VELUDO-DE-OLIVEIRA; IKEDA; CAMPOMAR, 2006a), foi utilizado um método adicional: as entrevistas também foram analisadas sob a ótica do sistema de valores de Floch (I990). Em respeito aos princípios metodológicos da análise do discurso por meio da semiótica discursiva de linha francesa, não foram consideradas nessa etapa as sequências A-C-V.

Nos discursos, surgiram indícios da presença de valores práticos (qualidade, quantidade e "não dá alergia”), críticos (custo/benefício) e utópicos (autoestima, ser respeitada). Sobre a ausência dos valores lúdicos, poder-se-ia argumentar que os depoimentos, marcados pela motivação de despertar o desejo dos homens ou a inveja de outras mulheres, indicariam uma valorização lúdica. Entretanto, a análise das entrevistas confirma os resultados obtidos com a aplicação da técnica de laddering, reforçando a interpretação de que tal motivação estaria ligada à busca de respeito e de autoestima. Dessa forma, perde-se o sentido de "atividade livre por excelência" que caracteriza a valorização lúdica nos termos de Floch (I990).

Da análise depreende-se o percurso apresentado na Figura 3, em que se verifica uma conciliação mítica entre valores práticos e utópicos.

\section{FIGURA 3}

\section{PERCURSO DE VALORIZAÇÃO}

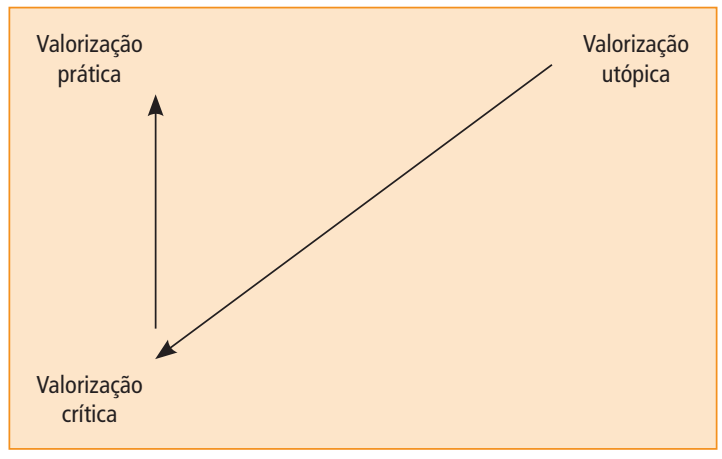

Fonte: Elaborada pelos autores. 


\section{CONCLUSÃO}

No Brasil, o mercado formado pelos consumidores de baixa renda tem apresentado crescimento significativo em seu potencial de consumo (BARROS, 2006). No entanto, seu restrito orçamento familiar ainda é limitante. Nesse contexto, necessidades básicas, como alimentação e moradia, não são, muitas vezes, plenamente satisfeitas (SILVA; PARENTE, 2007). Mesmo convivendo com tais restrições, mulheres consomem produtos de beleza que, à primeira vista, poderiam ser considerados supérfluos.

Os resultados aqui obtidos trazem evidências de que essas consumidoras buscam aumentar sua autoestima e seu respeito social pelo uso desses produtos. A autoestima, que surgiu das entrevistas como o valor mais importante, pode ser reforçada ou recuperada quando as mulheres sentem-se desejadas por seus parceiros ou por outros homens. Mais bonitas, ficam satisfeitas com sua imagem, e o "eu" real aproxima-se do "eu" ideal (BIZMAN; YINON, 2004). Ou quando, por estarem mais belas, diferenciam-se de mulheres do seu estrato social, assim obtendo reconhecimento (FONTES, 2009). Estar bela, portanto, torna-se uma obrigação (VILHENA; MEDEIROS; NOVAES, 2005).

Ser respeitada por classes sociais hierarquicamente superiores foi o segundo valor revelado pelas entrevistadas. A aparência parece ser uma poderosa ferramenta para diminuir a percepção de inferioridade causada por sua condição socioeconômica desfavorável, diminuindo também a percepção de discriminação pelo fato de ser pobre. Elas querem ser respeitadas no seu dia a dia, no ambiente de trabalho, nos supermercados (PARENTE; BARKI; KATO, 2005) e nas lojas onde compram (BARROS; ROCHA, 2009; CHAUVEL; SUAREZ, 2009; BARBOSA, HOR-MEYLL; MOTTA, 2009).

Embora possam surgir questionamentos quanto à extensão dos valores autoestima e reconhecimento social, como motivadores primários para a compra de produtos de beleza, para classes socioeconômicas mais favorecidas, os resultados aqui obtidos revelam dois aspectos que parecem ser diretamente relacionados às consumidoras de baixa renda.

Os relatos revelam forte percepção das entrevistadas de que sofrem discriminação social, inclusive em seu próprio ambiente. O uso de produtos de beleza seria, então, uma maneira de, pela aparência, reduzirem pistas visuais de sua condição social, evitando situações constrangedoras ou mesmo humilhantes. Mais do que um capricho, os produtos desempenhariam o papel de preservar a dignidade do indivíduo.

O segundo aspecto está relacionado à recuperação ou elevação da autoestima. As restrições financeiras constantes e, de forma geral, as duras condições de 
trabalho que enfrentam diariamente produzem sensação permanente de baixo poder, o que as conduziria ao consumo compensatório (RUCKER; GALINSKY, 2008). Uma das entrevistadas, faxineira, relatou que, após um dia de trabalho extenuante, a maquiagem e o cuidado com os cabelos eram indispensáveis, antes de retornar para casa, porque sentir-se mais bonita e cuidada era a forma que restava para reconquistar sua dignidade.

$\mathrm{O}$ valor percebido, entendido como o preço pago em relação à qualidade do produto, surgiu como importante fator de influência na decisão de compra de produtos de beleza. O preço parece ser fator eliminatório, já que a compra de itens caros desequilibraria o orçamento familiar, comprometendo ainda mais a satisfação de necessidades básicas da família. A qualidade percebida, entretanto, também parece ser crucial, já que, uma vez comprado o produto, seja ele barato ou caro, terá que ser totalmente utilizado, pois sua recompra seria proibitiva. As entrevistadas mostram-se muito conscientes quanto a gastos com produtos de beleza, somente comprando o que podem. A marca pode ser importante, mas como garantia de qualidade e não como símbolo de status.

\section{LIMITAÇÕES E RECOMENDAÇÕES PARA ESTUDOS FUTUROS}

Apesar das inúmeras vantagens, o método laddering apresenta limitações, sendo as mais citadas na literatura a dificuldade de sua utilização em larga escala, que limita seu uso a poucos respondentes, e o tempo despendido nas entrevistas (VELUDO-DE-OLIVEIRA; IKEDA, 2008).

Devido ao fato de as perguntas serem feitas repetidas vezes, as questões levantadas podem tornar-se óbvias e cansativas para os entrevistados (WOODRUFF; GARDIAL, I996). Além disso, muitas vezes o entrevistado não consegue pensar sobre a importância do tema abordado, ou nunca pensou anteriormente em relação à questão (REYNOLDS; GUTMAN, I988), não sabendo responder corretamente.

Durante a análise de conteúdo, pode ocorrer interferência dos pesquisadores, ao reconstruírem o significado dado pelos entrevistados (GRUNERT; GRUNERT, I995), o que se procurou minimizar com o emprego adicional da análise do discurso.

Estudos futuros poderão aprofundar o conhecimento sobre o tema, buscando representatividade que respalde a generalização dos achados aqui apresentados. Como existe limitação da aplicação da técnica laddering para amostras maiores, um processo caro que despenderia muito tempo, recomenda-se empregar técnicas 
de hard laddering - com a coleta de grande número de entrevistas por meio de questionários e o emprego de métodos quantitativos de análise (VELUDO-DE OLIVEIRA; IKEDA; CAMPOMAR, 2006a), como a association pattern technique - APT (FLORES NETO; SILVEIRA, 2007).

\section{VALUES THAT MOTIVATE LOW-INCOME WOMEN TO PURCHASE BEAUTY PRODUCTS}

\section{ABSTRACT}

This study sought to identify individual motives and values that could explain the purchase of beauty products (which would, under a first glimpse, to be considered as superfluous) by women who, in each consumer decision, experience intense pressure by the limited family budget. Some may even prefer to feed themselves poorly rather than forgo those items, which they consider very important for their daily lives. The means-end chain (GUTMAN, I982), and Rokeach's (I973) and Floch's (I990) types of values constituted the conceptual basis for the study. Seventeen in-depth interviews were conducted with low-income women living in the city of Rio de Janeiro. Besides the laddering technique (REYNOLD; GUTMAN, I988), the interviews were also interpreted by means of content and discourse analyses. Results provide evidence that, when buying beauty products, low-income women are primarily seeking to raise their self-esteem. Gaining the respect of higher social classes was the second most important value revealed: appearance seems to be a tool that low-income women use to reduce their perception of inferiority due to socio-economic disadvantage, also serving to diminish their perception of discrimination based on the fact of being poor. The interviewees displayed a high degree of conscientiousness with spending on beauty products, and declared to buy only what they could afford. Price seems to be a decisive factor, since the purchase of expensive products would unbalance the family budget, jeopardizing the satisfaction of basic needs. Perceived quality, however, also seems to be crucial, since once the product has been purchased, be it cheap or expensive, it must be fully utilized, given that repurchase would be prohibitive. Brand may be important, but only as a guarantee of quality, not as a guarantee of obtaining status. Results shed more light on some aspects related to consumer behaviors of social groups at the base of the pyramid, as values and motivations. It also offers contribution to the marketing mix planning for companies that intend to compete in the low-income market in Brazil. 


\section{KEYWORDS}

Values and consumption; Low-income women; Beauty products; BOP consumption; Disadvantaged consumers.

\section{VALORES QUE MOTIVAN EL CONSUMO DE PRODUCTOS DE BELLEZA POR MUJERES DE BAJOS INGRESOS}

\section{RESUMEN}

El artículo tiene como objetivo identificar valores individuales que motiven mujeres de bajos ingresos, viviendo con severas limitaciones financieras, a comprar productos de belleza, que podrían a primera vista ser considerados como superfluos. El modelo de cadena medios-fin (GUTMAN, I982) y las tipologías de valores de Rokeach (I973) y de Floch (I990) han constituido la base conceptual para el análisis. Se llevaron a cabo entrevistas en profundidad, empleando la técnica laddering (REYNOLD; GUTMAN, I988), con I7 mujeres de bajos ingresos residentes en la ciudad de Río de Janeiro. Las entrevistas también se interpretaron con el auxilio de análisis de contenido y de discurso. Los resultados arrojan evidencias de que, con el uso de productos de belleza, las consumidoras de bajos ingresos buscan elevar su autoestima, constantemente afligida por las restricciones que sufren debido a su condición financiera, que las sitúa en permanente situación de desventaja. También buscan, através de la belleza, adquirir el respeto de clases sociales jerárquicamente superiores, dado que la apariencia parece ser una manera eficaz de disminuir su percepción de discriminación por ser pobres. Las entrevistadas se mostraron muy conscientes en relación a sus limitaciones presupuestarias para el dispendio con productos de belleza, adquiriendo por tanto solamente lo que puedan pagar. La marca surgió como un factor importante en sus elecciones, no para tener status, sino como garantía de la calidad de los productos. El trabajo amplía el conocimiento sobre el comportamiento de consumo de los grupos sociales en la base de la pirámide, examinando cuestiones todavía poco exploradas, como valores de su subcultura. Bajo la óptica gerencial, presenta contribuciones para la gestión del mix de marketing de empresas que pretendan actuar en aquel mercado. 


\section{PALAVRAS CLAVE}

Valores y consumo; Mujeres de bajos ingresos; Productos de belleza; Consumo en la base de la pirámide; Consumidor desfavorecido.

\section{REFERÊNCIAS}

ABRIL; IBOPE. Entenda as mulheres da classe C. Disponível em: <http://mdemulher.abril.com.br/ revistas/midiakit/classe-c-no-brasil/index.html>. Acesso em: I3 set. 2009.

ALLEN, M. W. The attribute-mediation and product meaning approaches to the influence of human values on consumer choices. In: COLUMBUS, F. Advances in psychology research. Huntington: Nova Science Publishers, 2000. v. I, p. 3I-76.

ALLEN, M.; NG, S. The direct and indirect influences of human values on product ownership. Journal of Economics Psychology, v. 20, n. I, p. 5-39, I999.

ASSAD, M. M.; ARRUDA, M. C. Consumidor de baixa renda: o modelo de dinâmica do processo de compra. In: ENANPAD, 30., 2006, Salvador. Anais... Salvador: Anpad 2006. CD-ROM.

BARBOSA, P.; HOR-MEYLL, L.; MOTTA, P. O uso de celular pré-pago por consumidores de baixa renda. In: ROCHA, A.; SILVA, J. Consumo na base da pirâmide: estudos brasileiros. Rio de Janeiro: Mauad X, 2009. p. II3-I32.

BARROS, C. A invisibilidade do mercado de baixa renda nas pesquisas de marketing: as camadas populares consomem ou sobrevivem? In: ENCONTRO DE MARKETING DA ASSOCIAÇÃO NACIONAL DE PÓS-GRADUAÇÃO E PESQUISA EM ADMINISTRAÇÃO, 2., 2006, Rio de Janeiro. Anais... Rio de Janeiro: Anpad, 2006. CD-ROM.

BARROS, C. "Na internet, todo mundo é feliz": sociabilidade e familiaridade no universo das camadas populares In: ROCHA, A.; SILVA, J. Consumo na base da pirâmide: estudos brasileiros. Rio de Janeiro: Mauad X, 2009. p. 97-II2.

BARROS, C. F. P. Trocas, hierarquias e mediação: as dimensões culturais do consumo em um grupo de empregadas domésticas. 2007. Tese (Doutorado em Administração de empresas)-Universidade Federal do Rio de Janeiro, Rio de Janeiro, 2007.

BARROS, C.; ROCHA, E. Lógica de consumo em um grupo de camadas populares: uma visão antropológica de significados culturais. In: ROCHA, A.; SILVA, J. Consumo na base da pirâmide: estudos brasileiros. Rio de Janeiro: Mauad X, 2009, p. 3I-48.

BERTRAND, D. Caminhos da semiótica literária. São Paulo: Edusc, 2003.

BIZMAN, A.; YINON, Y. Social self-discrepancies from own and other standpoints and collective self-esteem. Journal of Social Psychology, v. I44, n. 2, p. IOI-II3, 2004.

BLOCH, P.; RICHINS, M. You look "marvelous": the pursuit of beauty and the marketing concept. Journal of Psychology Marketing, v. 9, n. I, p. 3-15, I992.

BOSTON CONSULTING GROUP. Mercados pouco explorados: descobrindo a classe C. The Boston Consulting Group, 2002.

BOUZÓN, P. G. O teu cabelo não nega? Um estudo de práticas e representações sobre cabelos. 2004. Dissertação (Mestrado em Administração)-Universidade Federal Fluminense, Niterói, 2004. 
CASOTTI; L.; SUAREZ, M.; DELIZA, R. Consumo de alimentos nas famílias de baixa renda: compartilhando achados, experiências e aprendizados. In: ROCHA, A.; SILVA, J. Consumo na base da pirâmide: estudos brasileiros. Rio de Janeiro: Mauad X, 2009. p. 225-244.

CASTILHOS, R.; ROSSI, C. Subindo o morro: consumo, posição social e distinção entre famílias de classes populares. In: ROCHA, A.; SILVA, J. Consumo na base da pirâmide: estudos brasileiros. Rio de Janeiro: Mauad X, 2009. p. 49-74.

CHAUVEL, M. A.; MATTOS, M. P. A. Z. Consumidores de baixa renda: uma revisão de achados de estudos feitos no Brasil. Cadernos Ebape.BR, v. 6, n. 2, p. I-I7, jun. 2008.

CHAUVEL, M.; SUAREZ, M. Consumidores pobres e insatisfação pós compra: "Eles não têm respeito pela gente”. In: ROCHA, A.; SILVA, J. Consumo na base da pirâmide: estudos brasileiros. Rio de Janeiro: Mauad X, 2009. p. I79-204.

CLAWSON, C.; VINSON, D. Human values: a historical and interdisciplinary analysis. Advances in Consumer Research, v. 5, n. I, p. 396-402, 1978.

DANTAS, S. S.; POIAN, A. A.; TORTORELLI, T. C.; FURLANETTO, K. Cosméticos para consumidoras jovens de baixa renda: mais que um produto uma atividade de lazer. In: SEMINÁRIOS EM ADMINISTRAÇÃO, I2. 20IO. Anais... São Paulo-USP, 20 Io.

DION, K.; BERSCHEID, E. What is beautiful is good. Journal of Personality and Social Psychology, v. 24, n. 3, p. $285-290,1972$.

DUBOIS, D.; RUCKER, D. D.; GALINSKY, A. D. Super size me: product size as a signal of status. Journal of Consumer Research, v. 38, p. IO47-IO62, Apr. 2012.

EAGLY, A.; ASHMORE, R.; MAKHIJANI, M.; LONGO, L. What is beautiful is good, but ...: a metaanalytic review of research on the physical attractiveness stereotype. Psychological Bulletin, v. IIo, n. I, p. I09-I28, I99I.

ECO, H. A história da beleza. Rio de Janeiro: Record, 2004.

ETCOFF, N. Survival of the prettiest: the science of beauty. New York: First Anchor Books, 2000.

FERREIRA, A. Novo dicionário da língua portuguesa. 2. ed. Rio de Janeiro: Nova Fronteira, I986.

FIORIN, J. L. Elementos da análise do discurso. São Paulo: Contexto, 2006.

FLOCH, J. M. Petites mythologies de l'oeil et de l'espirit: pour une sémiotique plastique. Paris-Amsterdã: Hadès-Benjamins, I985.

FONTES, O. Gênero, beleza e consumo: um estudo exploratório sobre o olhar masculino. 2009. Dissertação (Mestrado em Administração)-Universidade Federal do Rio de Janeiro, Rio de Janeiro, 2009. FUSTAINO, J.; YAMANOTO, C. S. O consumo de crédito no mercado de baixa renda: fatores contribuintes para o aumento das dívidas. In: ENCONTRO NACIONAL DA ASSOCIAÇÃO NACIONAL DOS PROGRAMAS DE PÓS-GRADUAÇÃO EM ADMINISTRAÇÃO, 33., 2009, São Paulo. Anais... Rio de Janeiro: Anpad, 2009.

GOLDENBERG, M. O corpo como capital: estudos sobre gênero, sexualidade e moda na cultura brasileira. São Paulo: Estação das Letras e Cores, 2007.

GREIMAS, A. Du sens II. Paris: Seuil, I983.

GREIMAS, A.; COURTÉS, J. Dicionário de semiótica. São Paulo: Contexto, 2008.

GROSSI, P.; MOTTA, P. C.; HOR-MEYLL, L. F. Risco percebido na compra de alimentos por consumidores de baixa renda. In: CHAUVEL, M.; COHEN, M. Ética, sustentabilidade e sociedade: desafios da nossa era. Rio de Janeiro: Mauad X, 2009. p. 2II-232. 
GRUNERT, K. G.; GRUNERT, S. C. Measuring subjective meaning structures by the laddering method: theoretical considerations and methodological problems. International Journal of Research in Marketing, v. I2, n. 3, p. 209-225, I995.

GUTMAN, J. A means-end chain model based on consumer categorization process. Journal of Marketing, v. 46, p. 60-72, I982.

HOLBROOK, M. Consumer value: a framework for analysis and research. New York: Routledge, I999. HOLBROOK, M.; MOORE, W. Feature interactions in consumer judgements of verbal versus pictorial presentations. Journal of Consumer Research, v. 8, p. I03-II3, Jun. I98I.

HOWARD, J. A. Consumer behavior: application and theory. New York: McGraw Hill, I977.

ISSA JR., E. Comportamento do consumidor de baixa renda: um estudo sobre o processo de compara de preservativos. 2004. Dissertação (Mestrado em Administração)-Universidade de São Paulo, São Paulo, 2004 .

JORDÃO, J. Beleza que põe mesa: a relação de trabalhadoras domésticas com mídia, beleza e consumo. 2008. Dissertação (Mestrado em Administração)-Universidade Federal de Goiás, Goiânia, 2008.

KAMINSKI, S. Valores, benefícios, atributos e dimensões simbólicas no consumo de música do estilo new metal: uma análise exploratória. 2004. Dissertação (Mestrado em Administração)-Universidade Federal do Paraná, Curitiba, 2004.

KARNANI, A. Fighting poverty together: rethinking strategies for business, governments, and civil society to reduce poverty. New York: Palgrave-MacMillan, 20 II.

LEÃO, A. E-value: um estudo sobre o customer value dos usuários do JB OnLine. 200I. Dissertação (Mestrado em Administração)-Universidade Federal de Pernambuco, Recife, 200I.

LEÃO, A.; MELLO, S. Marcas como busca por distinção social. In: ENCONTRO DE MARKETING DA ASSOCIAÇÃO NACIONAL DE PÓS-GRADUAÇÃO E PESQUISA EM ADMINISTRAÇÃO, 2008, Curitiba. Anais... Rio de Janeiro: Anpad, 2008. CD-ROM.

LEMES, W. Subjetividade e cultura: o sentido da beleza para a mulher. 2006. Dissertação (Mestrado em Administração)-Universidade Católica de Goiás, Goiânia, 2006.

LIPOVETSKY, G. O império do efêmero: a moda e seu destino nas sociedades contemporâneas. São Paulo: Companhia das Letras, I989.

MACHADO, M.; PEREIRA, S. Espelho, espelho meu, quem sou eu? Consumo estético e a construção da identidade da mulher. In: ENCONTRO DE MARKETING DA ASSOCIAÇÃO NACIONAL DE PÓS-GRADUAÇÃO E PESQUISA EM ADMINISTRAÇÃO, 20Io, Florianópolis. Anais... Rio de Janeiro: Anpad, 2oIo. CD-ROM.

MALHOTRA, N. Pesquisa de marketing: uma orientação aplicada. 4. ed. Porto Alegre: Bookman, 2006. MATTOS, M. P. O consumidor de baixa renda e sua relação com as marcas no processo de decisão de compra de refrigerante e sabão em pó. 2007. Dissertação (Mestrado em Administração)-Pontifícia Universidade Católica do Rio de Janeiro, Rio de Janeiro, 2007.

McCRACKEN, G. G. Culture and consumption: a theorectical account of the structure and movement of the cultural meaning of consumer goods. Journal of Consumer Research, v. I3, p. 7I-84, I986. MICK, D. G. Consumer research and semiotics: exploring the morphology of signs, symbols, and significance. Journal of Consumer Research, v. I3, p. I96-213, I986.

MOTTA, P. C.; CASARIN, T. How low-income consumers increase the amount of food to share with more. In: GLOBAL CONFERENCE ON BUSINESS \& ECONOMICS, 6., 2006, Boston. Proceedings... Boston: Harvard University, 2006. CD-ROM. 
NETO, M. F.; SILVEIRA, T. Uma abordagem metodológica mista sobre a cadeia de meios-fim. In: ENCONTRO DE MARKETING DA ASSOCIAÇÃO NACIONAL DE PÓS-GRADUAÇÃO E PESQUISA EM ADMINISTRAÇÃO, 2007, Rio de Janeiro. Anais... Rio de Janeiro: Anpad, 2007. CD-ROM. NOVAES, J.; VILHENA, J. De cinderela a moura torta: sobre a relação mulher, beleza e feiúra. Interações, v. 8, n. I5, p. 9-36, 2003.

PARENTE, J.; BARKI, E.; KATO, H. Consumidor de baixa renda: desvendando as motivações no varejo de alimentos. In: ENCONTRO DA ASSOCIAÇÃO NACIONAL DE PÓS-GRADUAÇÃO E PESQUISA EM ADMINISTRAÇÃO, 2005, Brasília. Anais... Rio de Janeiro: Anpad, 2005. CD-ROM. PITTA, D.; GUESALAGA, R.; MARSHALL, P. The quest for the fortune at the bottom of the pyramid: potential and challenges. Journal of Consumer Marketing, v. 25, n. 7, p. 393-40I, 2008.

PRAHALAD, C. K. A riqueza na base da pirâmide. São Paulo: Bookman, 2005.

QUEIROZ, R.; OTTA, E. A beleza em foco: condicionantes culturais e psicobiológicos na definição da estética corporal. In: QUEIROZ, R. (Org.). O corpo do brasileiro: estudos de estética e beleza. São Paulo: Senac, 2000.

RANGAN, V.; QUELCH, J.; HERRERO, G.; BARTON, B. Business solution for the global poor: creating social and economic value. San Francisco: Jossey-Bass, 2007.

REYNOLDS, T.; GUTMAN, J. Laddering theory, method, analysis and interpretation. Journal of Advertising, v. 28, n. I, p. II-3I, Feb./Mar. I988.

RICHINS, M. Valuing things: the public and private meaning of possessions. Journal of Consumer Research, v. 2I, p. 504-52I, I994.

ROCHA, A.; SILVA, J. Inclusão social e marketing na base da pirâmide: uma agenda de pesquisa. RAE - Eletrônica, v. 7, n. 2, 2008.

ROKEACH, M. The nature of human values. New York: Free Press, I973.

ROSÁRIO, F. Comportamento desviante e padrões estéticos: um estudo exploratório com mulheres que não pintam o cabelo. 2006. Dissertação (Mestrado em Administração)-Universidade Federal do Rio de Janeiro, Rio de Janeiro, 2006.

RUCKER, D.; GALINSKY, A. Desire to acquire: powerlessness and compensatory consumption. Journal of Consumer Research, v. 35, p. 257-267, Aug. 2008.

SCHWARTZ, S. H. Are there universal aspects in the content an structure of values? Journal of Social Issues, v. 50, p. I9-45, I994.

SCHWARTZ, S. H. Universales in the content and structure of values: theory and empirical tests in 20 countries. In: ZANNA, M. (Ed.) Advances in experimental social psychology. Nova York: Academic Press, I992, v. 25, p. I-65.

SCOTT, J. E.; LAMONT, L. M. Relating consumer values to consumer behavior: a model and method for investigation. In: GREER, T. Increasing marketing productivity. Chicago: American Marketing Association, I973.

SHETH, J.; NEWMAN, B.; GROSS, B. Consumption values and market choices: theory and application. Cincinnati: South Western, I99I.

SILVA, H.; PARENTE, J. O mercado de baixa renda em São Paulo: um estudo de segmentação baseado no orçamento familiar. In: ENCONTRO DA ASSOCIAÇÃO NACIONAL DE PÓS-GRADUAÇÃO E PESQUISA EM ADMINISTRAÇÃO, 2007, Rio de Janeiro. Anais... Rio de Janeiro: Anpad, 2007. CD-ROM. 
TEIXEIRA, M. L. M.; TORRES, M. G. da P. Valores humanos: teoria e aplicações. Introdução. Revista de Administração Mackenzie, v. Io, n. 3, p. 2-II, 2009.

TEIXEIRA, S. Produção e consumo social da beleza. Horizontes Antropológicos, v. 7, n. I6, p. I89220, $200 \mathrm{I}$.

TORRES, C. V.; ALLEN, M. W. Valores humanos e escolha do consumidor na Austrália e Brasil. Psicologia: Teoria e Pesquisa, v. 25, n. 4, p. 6II-620, 2009.

VALLETE-FLORENCE, P.; RAPACCHI, B. Improvements in means-end chain analysis: using graph theory and correspondence analysis. Journal of Advertising Research, v. 3I, n. I, p. 30-45, I99I. VANZELLOTTI, C. Esperança para dar e vender: a esperança no consumo de cosméticos anti-sinais. 2007. Dissertação (Mestrado em Administração)-Universidade Federal do Rio Grande do Sul, Porto Alegre, 2007.

VELUDO-DE-OLIVEIRA, T. M.; IKEDA, A. Uso e limitações do método laddering. Revista de Administração Mackenzie, v. 5, n. I, p. I97-222, 2004.

VELUDO-DE-OLIVEIRA, T. M.; IKEDA, A. O conceito de valor para o cliente: definições e implicações gerenciais em marketing. Gestão.org, UFPE, v. 3, n. I, p. 39-52, 2005.

VELUDO-DE-OLIVEIRA, T. M.; IKEDA, A. Valor em serviços educacionais. RAE-Eletrônica, v. 5, n. 2, 2006 .

VELUDO-DE-OLIVEIRA, T. M.; IKEDA, A. Laddering em pesquisa de marketing. Cadernos Ebape. $B R$, v. 6, n. I, p. I-I3, 2008.

VELUDO-DE-OLIVEIRA, T.; IKEDA, A.; CAMPOMAR, M. C. Laddering in the practice of marketing research: barriers and solutions. Qualitative Market Research, An International Journal, v. 9, n. 3, p. 297-306, 2006a.

VELUDO-DE-OLIVEIRA, T.; IKEDA, A.; CAMPOMAR, M. C. Discussing laddering application by the means-end chain theory. The Qualitative Report, v. II, n. 4, p. 626-642, Dec. 2006b.

VILHENA, J.; MEDEIROS, S.; NOVAES, J. A violência da imagem: estética, feminino e contemporaneidade. Revista Mal Estar e Subjetividade, Fortaleza, v. 5, n. I, p. I09-I44, 2005.

VINSON, D.; SCOTT, J.; LAMONT, L. The role of personal values in marketing and consumer behavior. Journal of Marketing, v. 2, p. 44-50, I977.

WEBSTER, M.; DRISKELL, J. Beauty as status. The American Journal of Sociology, v. 89, n. I, p. I40-I65, I983.

WOOD, V.; PITTA, D.; FRANZAK, F. Successful marketing by multinational firms to the bottom of the pyramid: connecting share of heart, global "umbrella brands", and responsible marketing. Journal of Consumer Marketing, v. 25, n. 7, p. 419-429, 2008.

WOODRUFF, R. Customer value: the next source of competitive advantage. Journal of Academy of Marketing Science, v. 35, n. 2, p. 139-I53, I997.

WOODRUFF, R.; GARDIAL, S. Know your customer: new approaches to understanding customer value and satisfaction. Malden: Blackwell, I996.

74 YOUNG, S.; FEIGIN, B. Using the benefit chain for improved strategy formulation. Journal of Marketing, v. 39, p. 72-74, I975. 